\title{
Chapter 1 \\ Serious Games: An Attractive Approach to Improve Awareness
}

\author{
Silvio Sorace, Elisabeth Quercia, Ernesto La Mattina, \\ Charalampos Z. Patrikakis, Liz Bacon, Georgios Loukas, \\ and Lachlan Mackinnon
}

\section{Introduction}

Community policing started in the United States in the second half of the century when the rise of social disorder and crime rates was so high that LEAs had to rethink about the efficiency of their relationship with citizens and about the crimefighting model in place (Crime Stoppers International 2017). The need for a new police model involved also in Europe. Recognizing that police can rarely solve public safety problems on their own, community policing encourages interactive partnerships with relevant stakeholders. Its philosophy influences the way that departments are organized and managed (personnel and technologies), encouraging the application of modern management practices for efficiency and effectiveness. These changes can be enabled by Serious games as a form of learning. Serious games generally aim to teach or train by realistically simulating some aspect of a real-world situation and allowing learners to explore in a manner that is highly interactive. In community policing, they can be used to assist training of LEAs and citizens in the uptake of technologies, such as mobile and web applications, and raise citizen awareness about the opportunities offered in community policing mechanisms and fostering citizen engagement.

\author{
S. Sorace $(\bowtie) \cdot$ E. Quercia $\cdot$ E. La Mattina \\ Engineering Ingegneria Informatica, Rome, Italy \\ e-mail: silvio.sorace@eng.it; elisabeth.quercia@eng.it; ernesto.lamattina@eng.it \\ C. Z. Patrikakis \\ Electronics Engineering Department, University of West Attica, Egaleo, Greece \\ e-mail: bpatr@puas.gr \\ L. Bacon · G. Loukas · L. Mackinnon \\ Computing and Information Systems, University of Greenwich, London, UK \\ e-mail: e.bacon@gre.ac.uk; g.loukas@gre.ac.uk; 1.mackinnon@gre.ac.uk


Community policing comprises three key components: Community Partnerships (collaborative partnerships between law enforcement agencies and citizens to address solutions to concrete, and sometimes urgent, urban security problems and increase trust in police); Organizational Transformation (the alignment of organizational management, structures, personnel, and information systems to support community partnerships); Problem Solving (the proactive and systematic examination and evaluation of the identified problems for addressing effective responses) (COPS - U.S. Department of Justice 2014). Serious games can therefore serve all three by supporting training of police academies, local police, municipalities and citizens. This paper presents their use in the context of the scenarios defined for the TRILLION (Patrikakis et al. 2017) (TRusted, CItizen - LEA coILaboratIon over sOcial Networks) project in five European cities (Lisbon, York, Ancona, Lecce and Eindhoven), which differ in terms of demographics, geography, culture and primary security threats. The training for citizens and for LEAs is outlined, highlighting their differences and the approach taken to provide practical games supporting the introduction of a community policing platform to citizens and officers.

\section{The Future of Law Enforcement}

Community policing has evolved into the preeminent reform goal in modern policing, which differs from traditional policing via a shift towards more citizen involvement, geographic focus, more opportunities for interaction with citizens, and an emphasis on prevention (Cordner 2014; TRILLION: TRusted, CItizen - LEA coILaboratIon over social Networks 2017). Naturally, this approach puts pressure at organizational level, for moving from a top-down approach of police management to a bottom-up approach, where citizens have a more active role. Another challenge relates to trust within and between the law enforcement agencies and the citizens. Motivation for engaging citizens in this community driven policing framework is also crucial. Community policing has been used successfully in crime reduction (Gill et al. 2014), extremism prevention (Schanzer et al. 2016), and even in counter terrorism (Dunn et al. 2016). In all cases, it was based on direct face-to-face or over-the-phone interaction between the community and LEAs. There is a growing realization that technology has the potential to accelerate the evolution towards more effective community policing (Lewis and Lewis 2012).

TRILLION takes the concept of technology-assisted community policing further and is currently developing a community policing platform, which aims to contribute to a safer society, encouraging interactive partnerships between law enforcement officers and the people they serve, implemented over an open, flexible, secure and resilient socio-technical set of tools. Using the TRILLION applications, citizens will be able to report crimes, suspicious behavior and incidents, identify hazards and assist law enforcement agents through active participation for achieving better urban security management. At the same time, LEAs will be able to detect incidents in a more efficient, content and context aware manner, and locate onsite 
Fig. 1.1 Use of technology and societal approval (RAND quadrants)

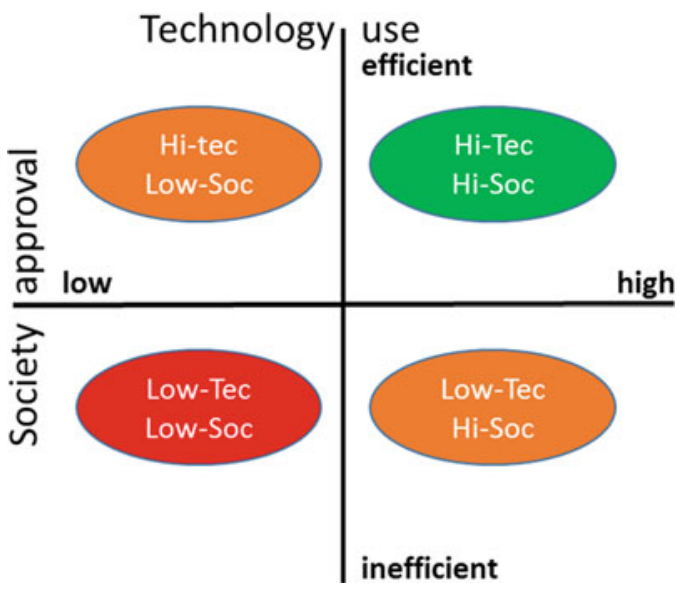

citizens. Community policing technology can improve effectiveness and efficiency but, if used incorrectly, could be perceived as intrusive, losing public support. For a starting point on how LEAs and Citizens collaborate towards a safer society, and to focus on a plausible future, the approach proposed by the RAND Corporation ${ }^{1}$ has been adopted. RAND used several techniques to develop their scenarios, presented in a matrix where each axis represents extremes at one side, enabling each quadrant to represent a clear and distinct scenario domain.

To establish a reliable scenario framework and having in mind the importance of trust between citizens and LEAs, the adoption of the methodology proposed by RAND (Siberglitt et al. 2015) represents a key factor. RAND's chart is based on the observation that the most important factors driving the future of law enforcement fall into two categories: Technology and Society. The effectiveness of the technology used by LEAs to accomplice their missions depends on the level of technology (vertical axis) and the extent to which LEA practices are accepted by society (horizontal axis). As presented in Fig. 1.1, the quadrants delimited by technology and society, create four different situations/futures, where moving to the upper right corner is the target for the serious games. In the Hi-Tec/Hi-Soc (upper right) quadrant, LEAs use advanced technology for dealing with different situations, enjoy societal support by the public. In the Low-Tec/Hi-Soc (lower right) quadrant, LEAs use obsolete technologies, but society continues to support them. In the Hi-Tec/LowSoc (upper left) quadrant, LEAs have the advantage in use of technology, but have lost society's trust, which opposes every action they take. In the Low-Tec/Low-Soc (lower left) quadrant, LEAs use old technologies, and have to face a society which opposes every LEA measure and action.

\footnotetext{
${ }^{1}$ Silberglitt R, Brian G. Chow, John S. Hollywood, Dulani Woods, Mikhail Zaydman and Brian A. Jackson. Visions of Law Enforcement Technology in the Period 2024-2034: Report of the Law Enforcement Futuring Workshop. Santa Monica, CA: RAND Corporation,: 2015.
} 


\section{TRILLION's Serious Games}

The TRILLION serious games were designed to be simple, easy to use, and enabling and facilitating best practices proposed in community policing.

\section{Serious Games for Citizens}

The serious game platform/application for citizens focuses on location, communication and interaction awareness. Its scenarios were designed having in mind technological and societal challenges taking into account the RAND approach. Scenarios are driven by how advances in technology are adopted and by how laws and LEAs evolve and are viewed by the public, which determines the effects of the evolution of society on law enforcement. At the end of the game, citizens are encouraged to download the mobile and wearable TRILLION apps and use them in real life to be engaged in community policing.

Game Scenarios The implemented scenarios are represented by non-linear storytelling, and supported by location-based mobile technologies, that will allow players to interact with virtual characters and items across an area. Virtual items collected during the gaming session will be used by players when they face the virtual event. Through creative entertainment, the serious games creators/masters, convey a positive message and "recommended behaviours" in the specific circumstances implemented in a scenario, which should be meaningful and realistic.

Architecture The architectural solution implemented for serious games is the client-server model. The client runs on mobile personal devices for the computational part, while the server side provides data regarding the games' list and data model linked to a game (items, characters, events, requirements, actions).

Game Elements The main game elements are items, which are objects scattered within the boundaries of the game area and are not always useful towards the game's goal (they could be used by the game master to divert the player's attention); $\underline{\text { characters, }}$, which are virtual people usually linked with an audio file; events, which need the citizen's reaction; and actions, which are selected by the player once an event position is reached. At the end of the game, a debriefing session allows to learn different/better behaviors and evaluates whether the goals were achieved, including fostering collaborative gameplay and behavior; and increase citizen awareness on collaboration with LEAs.

Communities For enabling the engagement and the collaboration of citizens/players, a community service has been created. The purpose is to stimulate discussions around the themes of the project and to enhance and strengthen the LEOs - Citizens relationship, especially for convincing reluctant citizens who see LEO's authority as an intrusion in their lives. 


\section{Serious Games for LEAs}

The purpose of the game was to develop the skills of the LEOs in interacting with the public using the TRILLION solutions, and because its focus is on community partnership and the future use of technology by both citizens and the police, the game could be considered to sit in the Hi-Tec/Hi-Soc, upper right corner of the RAND quadrant. The scenario chosen was on antisocial behavior, which was was felt to be important to all participating end users, in contrast to what would be a more rare event, such as a terrorist incident. To ensure the design of the game scenario was as realistic as possible, an Senior Policing, Border and Security Consultant was engaged to design the game scenario. The game platform used was Pandora ${ }^{+}$ (Bacon et al. 2017), originally developed for the 2010-2012 EU FP7 project entitled "Advanced Training Environment for Crisis Scenarios" (Bacon et al. 2012a, b; Mackinnon et al. 2013). The Pandora ${ }^{+}$training tool is a cloud-based client-server system which runs on a desktop or mobile device. Whilst it can be used in multiple ways, there are two core modes of use: (a) With a trainer of a group of people all working through the same game scenario, or (b) with trainees working through their own game scenario independently of a trainer. For this game, the second mode was deemed the most appropriate, i.e. each LEA trainee would play their own game. The Pandora ${ }^{+}$training tool is designed to provide an immersive multimedia experience to the player(s), and works by delivering an unfolding series of events as a situation develops, that requires LEA involvement. An example is a TRILLION citizen reporting on a fight breaking out who submits details of the suspect to the police through the TRILLION platform, sending in pictures of the incident or describing a suspect etc. The role of the trainee is to decide the appropriate TRILLION-relevant communication with the citizens, to reassure them, warn them or get further information. Note that the Pandora ${ }^{+}$tool has the capability to change the scenario and outcomes depending on how the player responds at different points in the game, if appropriate.

Learning Outcomes The focus of the game for the LEOs was on the communication with the citizen and their ability to compose appropriate messages when presented with different situations and responses from citizens. The learning outcomes identified for this training exercise were designed to enable the trainee to:

1. Utilise TRILLION in line with its core objectives.

2. Appreciate how a social media TRILLION-style police communication tool can assist community policing objectives and outcomes.

3. Create balanced and appropriate public safety communication messages.

4. Create balanced and appropriate messages for mobilising support from citizens for community safety goals and police efficiency.

5. Create balanced and appropriate messages for mobilising support from citizens for police investigation goals \& police efficiency. 


\section{Game Elements}

Characters The LEO (being trained), four citizens who witness the anti-social behaviour, community police colleagues, paramedics, trusted TRILLION users and two security professionals.

Events These represent something that is happening, which may just be information or a situation update, or may require a response or action by the trainee.

Action During the scenario, the trainees were asked for six text responses which they had to compose, regarding their use of the TRILLION services.

Execution of the Game The final version of the scenario was entitled "Episode in the day of a community police officer" and lasted for about $13 \mathrm{~min}$. The length was designed to be manageable within an appropriate timeframe / attention span of the participants, without making it too complex, whilst also being sufficient to achieve the learning outcomes. The games were designed separately to ensure a consistent experience for both the citizens and the LEOs thus allowing the performance of each participant to be appropriately evaluated within the group, as everyone would have the same experience.

The game was run in Lisbon, York, Ancona, Lecce and Eindhoven, and the scenario was presented to the participants in their native language. Participants were also able to respond in their native language and the results were translated into English so they could be analysed by the same team to ensure consistency. Tablets were used by the LEOs to access the system. There was also one person who was present at all the trials to ensure they were conducted in a consistent manner. In terms of the actual game playing event, a briefing was provided to the LEOs beforehand on what they would experience and how to access the system. Once the game was started by the LEO, the events were delivered at fixed times (the participants were unable to slow down or speed up). After the game was finished, the person running the training session ran a debriefing session which was an important part of the learning. The scenario author had provided guidance on the key aspects to look for in the messages sent by the LEOs, such as whether it was clear who the message was sent from and directed to, whether the LEO made the type of incident, the location and timing clear, whether the request of an intended recipient was appropriately concise, clear and unambiguous, whether the LEO sought to reassure a citizen to mitigate a sense of undue fear, whether the Police message / request was balanced and proportionate to the type of incident / action requested and relevant to required policing goals, etc. The scenario also provided an example of a good answer for each of the six messages required of the LEOs. A discussion about how each person had approached this, what they thought was important in each message etc. was discussed. 


\section{Results}

Since the scope of the games is to move the citizens' position to the upper right corner in the quadrant, the same questionnaire was submitted twice: before and after playing. The questionnaire included questions to investigate social aspects and position Citizens' perception in the RAND quadrant. The number of LEOs at each event ranged from 9 to 15 and the number of citizens from 20 to 25 . When the responses were analysed, the match was not high and not all responses were complete. There were a number of explanations for this, firstly the time to respond was relatively short, there are cultural differences in the style of police communication and police officers are generally not trained in this style of communication with the public. In some cases, the LEOs did not come as a group but in couples during the day, which might have affected their approach and attitude. Overall, the LEOs were positive about the TRILLION functionalities and their use in everyday life. According to citizens' and LEOs' answers to the questionnaire, due to reported constraints, the real initial position of the test bed communities was set in the middle with a slight propensity to the right hand side (Fig. 1.2). In summary, the public is often concerned with immediate response to incidents, there is a lack of explanation as to when and why technology is used, and there is little sharing of information. Also, response times can be slow.

After playing, the same questionnaire was submitted to the players for the second time. The responses were analysed and the new position, as expected, was in the upper right hand quadrant.

Fig. 1.2 Initial and final position (before and after playing)

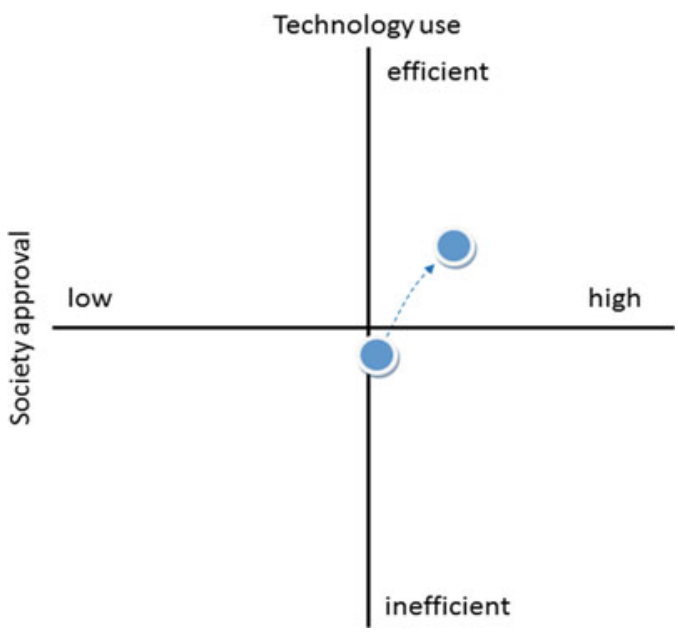




\section{Conclusions}

Community policing is gradually becoming synonymous to modern policing, but from a technological perspective, this process is supported by disjointed local initiatives, including collaborative software tools and social media monitoring services coming from National and European research initiatives like TRILLION. In particular TRILLION, serious games are used to train and educate the community in order to stimulate discussion and create awareness around the community policing mechanisms and plans and to transform the LEA-Citizen relationship for the better, especially welcoming and encouraging citizens who see LEO's authority as an intrusion in their lives. Serious games constitute an ambitious offering, whose components are already evaluated in live trials in several locations in Europe, and in close collaboration with a variety of LEAs. The RAND document was used to understand the effectiveness of serious games. While the results coming from the serious games for citizens helped us to detect the initial and the final position of the citizens in the RAND chart, the results coming from the serious games for LEAs could be appreciated only after a long-term period.

Acknowledgments This work is funded by the European Commission under grant number H2020-FCT-2014, REA grant agreement $n^{\circ}$ [653256]. The support is gratefully acknowledged.

\section{References}

Bacon, L., MacKinnon, L., Cesta, A., \& Cortellessa, G. (2012a). Developing a smart environment for crisis management training. Special edition of the Journal of Ambient Intelligence and Humanized Computing, entitled Smart Environments and Collective Computational Intelligence for Disaster Management, 3(2). https://doi.org/10.1007/s12652-012-0124-0.

Bacon, L., Cesta, A., Coraci, L., Cortellessa, G., Benedictis, R. D., Grilli, S., Polutnik, J., \& Strickland, K. (2012b, August). Training crisis managers with PANDORA. In ECAI, the Biennial European Conference on Artificial Intelligence (pp. 27-31). Montpelier, France.

Bacon, L., MacKinnon, L., \& Kananda, D. Supporting real-time decision making under stress in an online training environment. Published Feb 2017 in The IEEE Journal of Latin-American Learning Technologies (IEEE-RITA, IEEE - Revista Iberoamericana de Technologias del Aprendizaje) (Vol. 12, No. 1, pp. 52-61). Print ISSN: 1932-8540. Online ISSN: 1932-8540. Digital Object Identifier: https://doi.org/10.1109/RITA.2017.2659021.

COPS - U.S. Department of Justice. (2014). Community policing defined [Online]. Available at: ric-zai-inc.com/Publications/cops-p157-pub.pdf.

Cordner, G. (2014). Community policing. In M. D. Reisig \& R. J. Kane (Eds.), The Oxford handbook of police and policing (pp. 148-171). Oxford: Oxford University Press.

Crime Stoppers International. https://csiworld.org/. Last accessed on August 2017.

Dunn, K. M., Atie, R., Kennedy, M., Ali, J. A., O'Reilly, J., \& Rogerson, L. (2016). Can you use community policing for counter terrorism? Evidence from NSW, Australia. Police Practice and Research, 17(3), 196-211.

Gill, C., Weisburd, D., Telep, C. W., Vitter, Z., \& Bennett, T. (2014). Community-oriented policing to reduce crime, disorder and fear and increase satisfaction and legitimacy among citizens: A systematic review. Journal of Experimental Criminology, 10(4), 399. 
Lewis, S., \& Lewis, D. A. (2012, May). Examining technology that supports community policing. In Proceedings of the SIGCHI Conference on Human Factors in Computing Systems (pp. 13711380). ACM.

Mackinnon, L., Bacon, L., Cortellessa, G., Cesta, A. (2013, May). Using emotional intelligence in training crisis managers: The Pandora approach. The International Journal of Distance Education Technologies (IJDET), 11(2), 66-95, IGI Global.

Patrikakis, C., Konstantas, A., Kogias, D., \& Choras, M. (2017). TRILLION project approach on scenarios definition for citizen security services. To appear in International Journal of Electronic Governance.

Schanzer, D. H., Kurzman, C., Toliver, J., \& Miller, E. (2016). The challenge and promise of using community policing strategies to prevent violent extremism: A call for community partnerships with law enforcement to enhance public safety. Durham: Triangle Center on Terrorism and Homeland Security.

Siberglitt, R., Chow, B. G., Hollywood, J. S., Woods, D., Zaydman, M., \& Jackson, B. A. (2015). Visions of law enforcement technology in the period 2024-2034. Santa Monica: RAND Corporation.

TRILLION: TRusted, CItizen - LEA coILaboratIon over social Networks. (2017). http://trillionproject.eng.it. Deliverable 2.1 "Creation and Management of User Community"

Open Access This chapter is licensed under the terms of the Creative Commons Attribution 4.0 International License (http://creativecommons.org/licenses/by/4.0/), which permits use, sharing, adaptation, distribution and reproduction in any medium or format, as long as you give appropriate credit to the original author(s) and the source, provide a link to the Creative Commons license and indicate if changes were made.

The images or other third party material in this chapter are included in the chapter's Creative Commons license, unless indicated otherwise in a credit line to the material. If material is not included in the chapter's Creative Commons license and your intended use is not permitted by statutory regulation or exceeds the permitted use, you will need to obtain permission directly from the copyright holder. 